\title{
Incidental Finding Of Posterior Fossa Epidermoid, In A Head Trauma Patient: A Case Report
}

Banskota NP ${ }^{1}$, Singh $\mathrm{K}^{2}$

\begin{abstract}
Incidental findings of brain lesions in head injury are seen frequently. In our region NCC is common, but in literature meningioma and arachnoid cyst are common. Here we report a case of incidental finding of posterior fossa epidermoid in a 25 years old male patient who had history of minor head trauma which was operated with relatively uneventful post operative period.
\end{abstract}

\section{INTRODUCTION}

Epidermoid cysts (sebaceous cysts) are benign congenital lesions of ectodermal origin. They account for approximately $1 \%$ of all intracranial tumors. Although being congenital, patients are usually not symptomatic until they are aged $20-40$ years. They frequently occur at the cerebellopontine angles and parasellar regions. Most common site being the cerebellopontine angle (40\%$50 \%$ ), where they represent the third most frequent tumor in this location, after acoustic schwannoma and meningioma1.

Incidental findings on computed tomography (CT) scans are occasionally noted in patients presenting with head injury. Since it can be assumed that head injured patients are of normal health status before the accident, these findings may be a representation of their frequency in the general population2.

\section{CASE REPORT}

A 17 years old male was brought to emergency with history of road traffic accident. He had mild head injury and superficial injuries. After symptomatic management CT scan head was done as it was a medicolegal case. CT head revealed posterior fossa lesion. MRI was done to plan for surgery which revealed vermian tumor D/D epidermoid or medulloblastoma. After initial management patient was discharged to follow up for tumor resection.

On follow up patient was admitted, on second day he developed seizure. After management of seizure patient was prepared for surgery. On Preanesthetic check up atrial septal defect and valvular heart disease was also found.After suboccipital craneictomy, the lesion was confirmed to be epidermoid tumor on gross examination and also by histopathological examination. On $3^{\text {rd }}$ post operative day he developed pseudomeningocele which was managed conservatively. He also developed features of meningism so

1. Dr. Narendra Prasad Baskota

2. Dr. K. Singh

Address for correspondence:

Dr. Narendra Prasad Baskota

Consultant

Department of Neurosurgery

Nepalgunj Medical College \& Teaching Hospital

Kohalpur, Banke, Nepal
CSF was sent which was normal. Patient was symptom free and stable later and got discharged with advise to follow up in cardiac surgical centre for congenital heart disease.
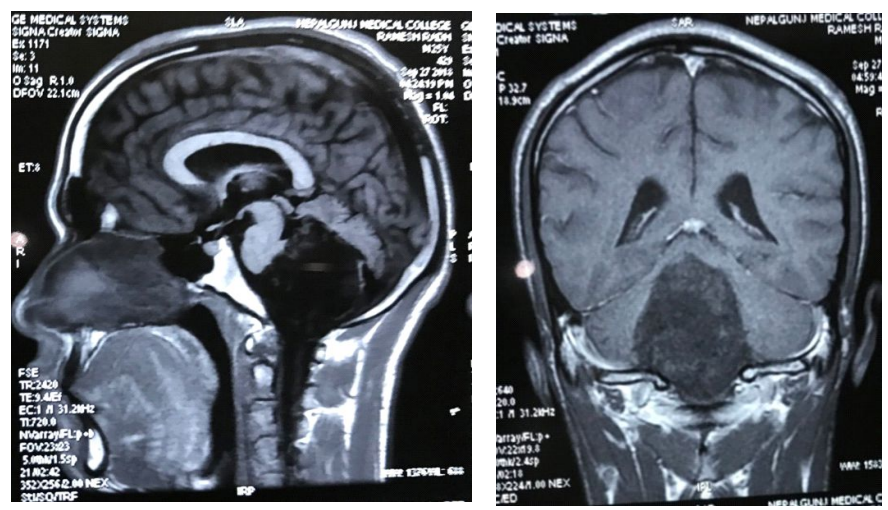

Figure 1 and 2: MRI showing lesion in posterior fossa(midline)
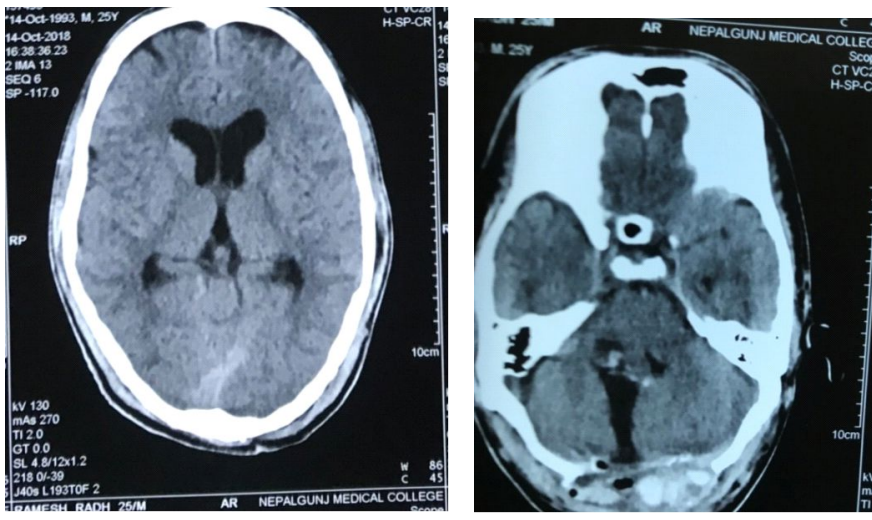

Figure 3 and 4: Post operative CT scan pictures 


\section{DISCUSSION}

Epidermoid cysts can occur throughout the neuroaxis, most commonly in the cerebellopontine angles (40-50\%) and the parasellar region1. The proposed embryological pathogenesis of the typical epidermoid cyst involves trapped ectodermal components travelling along the otic vesicles during neural tube closure, thus accounting for the propensity for its location at the cerebellopontine angles5. However in this case it was a vermian tumor.

Computed tomographic features for the typical epidermoid cysts include a hyperdense lobulated mass without contrast enhancement. Usually in mild head trauma case $\mathrm{CT}$ is not done but as it was a Medicolegal case (RTA), CT was done on victim's request and lesion was found incidently. Incidental finding of posterior fossa tumor is about 0.4 to $1 \%$ of intracranial space occupying lesion2.

Epilepsy secondary to epidermoid cyst is rare and its epileptogenesis mechanism is not fully clarified. It may assign to infiltration of brain tissue by the cyst, chemical meningitis, or an architectural change in epileptogenic aeas6 .Our patient had only one episode of seizure which was managed and it did not recur

On $3^{\text {rd }}$ post operative day our patient developed pseudomeningocele. Reported pseudomeningocele rates from posterior fossa interventions range from $4 \%$ to $28 \% 7$.

\section{CONCLUSION}

We encounter incidental asymptomatic brain lesion on CT head for head injury. Lesion was confirmed to be posterior fossa epidermoid by gross examination and histopathology.

\section{REFERENCES}

1. Epidermoid cyst of posterior fossa:case report. J. Bras. Patol. Med. Lab. vol.47 no.1 Rio de Janeiro Feb. 2011

2. Incidental cranial CT findings in head injury patient in Nigerian tereiary hospital. J Emerg Trauma Shock. 2015 Apr-Jun; 8(2): 77-82.

3. Atypical Intracranial Epidermoid Cysts: Rare Anomalies with Unique Radiological FeaturesCase Rep Radiol. 2015; 2015: 528632.

4. Incidental findings in brain computed tomography scans of 3000 head trauma patients. Surg Neurol. 2005 Jun;63(6):550-3; discussion 553.

5. Intracerebral epidermoid tumor: pathogenesis of intraparenchymal location and magnetic resonance imaging findings. Journal of Neuroradiology.

2006;33(4):269-270
6. Giant Epidermoid Cyst:A Rare Cause Of Temporal Lhobe Epilepsy. J Neurol Surg Rep. 2017 Jul; 78(3): e101-e105.

7. Revision surgery for Chiari malformation decompression. Mazzola CA, Fried AH. Neurosurg Focus. 2003;15:0. 